\title{
Genistein-Induced Apoptosis Affects Human Telomerase Reverse Transcriptase Activity in Acute Promyelocytic Leukemia
}

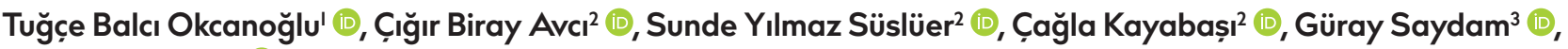 \\ Cumhur Gündüz² (i)
}

'Department of Medical Biology, Near East University Vocational School of Health Services, Nicosia, Cyprus

2Department of Medical Biology, Ege University School of Medicine, İzmir, Turkey

${ }^{3}$ Department of Hematology, Ege University School of Medicine, İzmir, Turkey

ORCID iDs of the authors: C. B. A. 0000-0002-2748-3I24; S. Y. S. 0000-0002-0535-I50X; C. K. 0000-0002-6797-7655; G. S. 0000-000I8646-1673; C. G. 0000-0002-6593-3237.

Cite this article as: Okcanoğlu TB, Avcı C̣B, Yılmaz Süslüer S, Kayabașı Ç, Saydam G, Gündüz C. Genistein-Induced Apoptosis Affects Human Telomerase Reverse Transcriptase Activity in Acute Promyelocytic Leukemia. Cyprus J Med Sci 2020; 5(2): 153-6.

\section{BACKGROUND/AIMS}

The purpose of this study was to research the effects of genistein on telomerase activity and apoptosis in an acute promyelocytic leukemia cell line (HL-60).

\section{MATERIAL and METHODS}

In HL-60 cells, the cytotoxic effect of commercially available genistein was evaluated by the XTT method. The XTT method is a Cell Proliferation Assay. The Annexin V-EGFP method was used to determine apoptosis. The human telomerase reverse transcriptase (hTERT) is a marker of telomerase activity. hTERT gene expression analysis was performed by LightCycler real-time RT-PCR.

\section{RESULTS}

In HL-60 cells, the IC50 of genistein was found to be $50 \mu \mathrm{M}$ at 72 hours. It was observed that the induction of apoptosis was 4.25 -fold higher compared to the genistein untreated cells used as the control group. Compared to the control group, hTERT activity was found to decrease by $5.16,3.81$ and 5.04 -fold at 24,48 and 72 hours, respectively.

\section{CONCLUSION}

Induced apoptosis of HL-60 cells by the reduction of human telomerase reverse transcriptase activity may be a beneficial parameter in leukemia patients.

Keywords: Apoptosis, Genistein, HL-60, hTERT

\section{INTRODUCTION}

Acute myeloid leukemia ( $A M L)$ is a heterogeneous group of hematopoietic malignancies characterized by the proliferation and maturation of myeloid blasts in bone marrow and blood (I).

Acute promyelocytic leukemia (APL) is characterized by translocation $+(15 ; 17)$. This translocation is responsible for the production of promyelocytic leukemia / retinoic acid receptor $\alpha$ (PML/RAR $\alpha$ ) fusion protein, which leads to inhibition of the differentiation of myeloid cells (2). Telomerase consists of two main components ( $h T E R T$ and human telomerase RNA (hTR) in a ribonucleoprotein structure. High telomerase activity is seen in most malignant cells. Specific expression of telomerase hTERT in most tumor types provides good separation between cancerous and normal cells. hTERT expression is associated with human cells (3). Inhibition of hTERT expression is shown as a therapeutic target to terminate telomerase activity in cancer cells. Several studies have been conducted to inhibit telomerase activity in promyelocytic leukemia with arsenic and retinoid. Expression of hTERT in cultured human primary cells has been shown to allow for reactivation of telomerase activity and to promote immortal cell proliferation (4). 
Genistein, an isoflavonoid compound derived from soybeans, has been shown to benefit several cells. Most of the flavonoids inhibit Topoisomerase I and Topoisomerase I| (5). Studies are showing that genistein induces apoptosis, anti-fiber proliferation, and inactivation of the MAPK pathway. Researches have also been performed on leukemia cells (6).

Genistein is a potent tyrosine kinase inhibitor that exhibits estrogen receptor binding activation and DNA topoisomerase II inhibition. Also, down-regulation of the PI3K/Akt and NF-kB signaling pathways leads to inhibition or activation of MAP kinase in the $\mathrm{G} 2 / \mathrm{M}$ arrest, produced by the change of cell cycle regulatory proteins (7).

Genistein has an inhibitory effect on c-Myc oncogene. This inhibition is possible by the inhibition of tyrosine kinase activity. It affects tyrosine kinase activity and suppresses c-Myc activity and stops cell cycle. (8). Genistein suppresses the G2/M cell cycle and expresses markers of differentiation in human acute myeloid leukemia cell lines; genistein has been shown to increase differentiation by cooperating with ATRA (7). In this study, the effect of genistein on apoptosis and Human Telomerase Reverse Transcriptase Activity was investigated in acute promyelocytic cell lines.

\section{MATERIAL and METHODS}

\section{Cell Culture and Chemicals}

Genistein (Sigma Chemical Co., St. Louis Missouri) and the HL 60 cell line (ATCC, USA) are commercially available. The chemicals were diluted with $0.1 \%$ dimethylsulphoxide (DMSO) (Sigma -Aldrich). The HL-60 cell line was reproduced using RPMI-I640 (Sigma -Aldrich) medium containing $10000 \mathrm{U} / \mathrm{mL}$ penicillin, $10 \mathrm{mg} / \mathrm{mL}$ streptomycin and $10 \%$ inactive fetal bovine serum (FBS) (Sigma-Aldrich), $1 \%$ L-glutamine (Sigma-Aldrich). It was incubated at $37 \circ \mathrm{C}$ and in a $95 \%$ humidity, $5 \% \mathrm{CO}_{2}$ incubator. Our study was conducted according to the Helsinki Declaration.

\section{XTT Assay}

HL-60 cells $\left(2 \times 10^{5}\right.$ cells $\left./ \mathrm{mL}\right)$ were plated on 96-well plates and incubated for 24 hours. At $24 \mathrm{~h}$, cell viability was measured with the trypan blue dye exclusion test. HL-60 cells treated with genistein at concentrations ranging from 0 to 100 $\mu \mathrm{M}$ and were incubated for 24, 48 and 72 hours. Cytotoxicity of genistein was determined according to the kit protocol with the XTT kit (Cell Proliferation Kit, Roche). Cells without genistein treated were used as control. The optical density (OD) of each well was read in the microplate reader (Multiskan FC, Thermo) with 450 and 620-nm reference wavelength. Cell viability was determined by proportioning the $O D$ values according to the control.

\section{Main Points:}

- Genistein has anti-proliferative effect in acute promyelocytic leukemia cell line.

- In acute promyelocytic leukemia cells, genistein was very effective on the hTERT gene expression.

- Genistein and hTERT activity may play a role in the treatment of acute promyelocytic leukemia.

\section{Apoptosis Assay}

The apoptotic effect of genistein's $I C_{50}$ dose was investigated in the HL-60 cell line. HL-60 cells $\left(5 \times 10^{5}\right.$ cells $\left./ \mathrm{mL}\right)$ were placed in 6 wells and treated with genistein's $I C_{50}$ dose for hours. Acridine orange/ethidium bromide apoptosis assay was performed as described previously (8). The number of apoptotic, necrotic and live cells (Figure I) were counted using a fluorescence microscope (BX-50, Olympus). The percentage of apoptosis was calculated as the total number of apoptotic cells divided by the total number of cells multiplied by 100.

\section{Isolation of tRNA and hTERT Gene Expression Analysis}

Total RNA (High Pure RNA Isolation Kit, Roche, Germany) was isolated from the cells exposed to doses of $\mathrm{IC}_{50}$ at 24,48 , and 72 hours. cDNA synthesis was performed using a RT2 first Strand Kit (Sigma, Germany). hTERT gene expression analysis was performed with a LightCycler real-time RT-PCR using a Lightcycler TeloTAGGG hTERT Quantification Kit (Roche, Germany). and was normalized to Porphobilinogen deaminase gene expression. Changes in hTERT gene expressions (fold change) were calculated by the $2^{-\triangle \triangle C T}$ method.

\section{Statistical analysis}

The mean and standard deviation was calculated by using Excel 2016 (Microsoft). The $I_{50}$ value was calculated using the log (inhibitor) vs normalized response - variable slope model in Prism (GraphPad). A comparison of the two groups was analyzed using the Student's t test in Prism (GraphPad). Gene expression data were analyzed by the $2^{-\triangle \Delta C T}$ method, according to the Light Cycler 480 Quantification Software program (Roche, Germany). The change in hTERT expression of $\geq \pm 2$-fold change according to the control group and $p$ values $<0.05$ were considered significant.

\section{RESULTS}

The IC50 value of genistein was found to be $50 \mu \mathrm{M}$ in a timeand dose-dependent manner in the HL-60 cells (Figure 2). We determined that the induction of apoptosis was significantly increased by 4.25 -fold in the genistein-treated HL-60 cells $(p<0.05$, Figure 3$)$. The activity of hTERT in the genistein-treat-

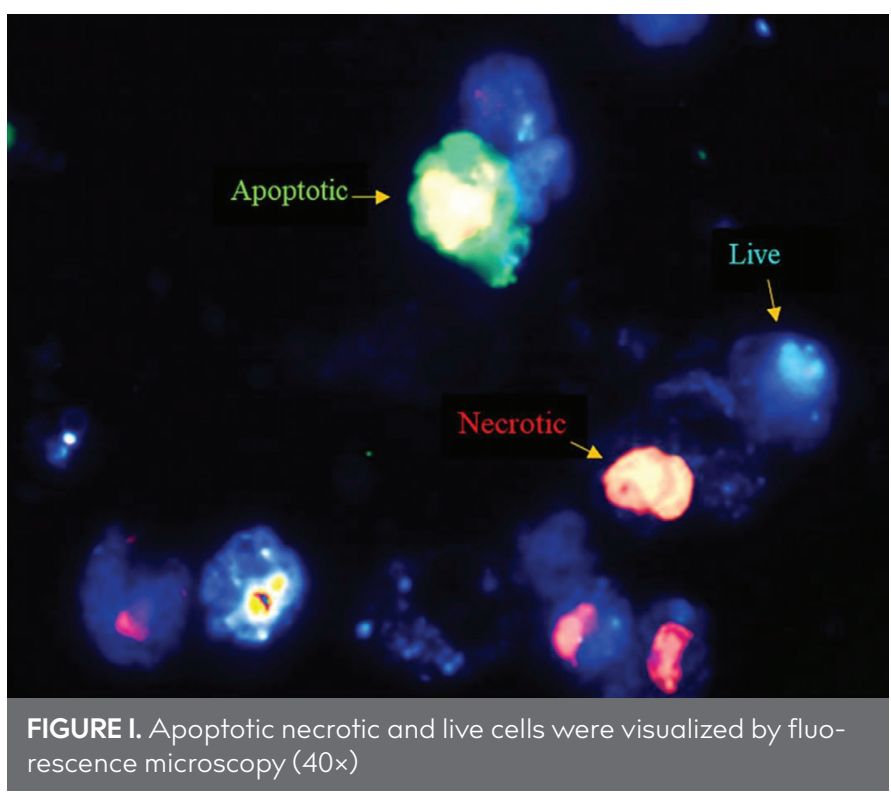




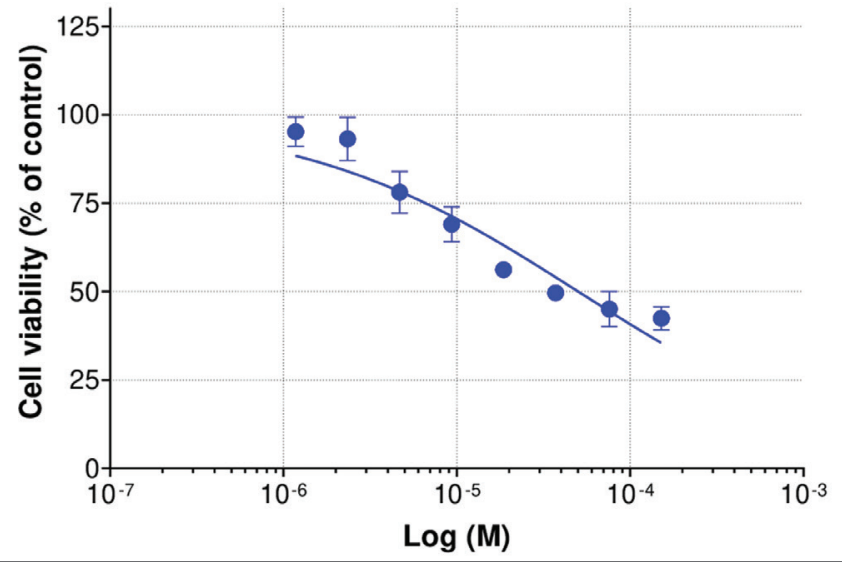

FIGURE 2. IC $C_{50}$ dose of genistein in $\mathrm{HL}-60$ cell line

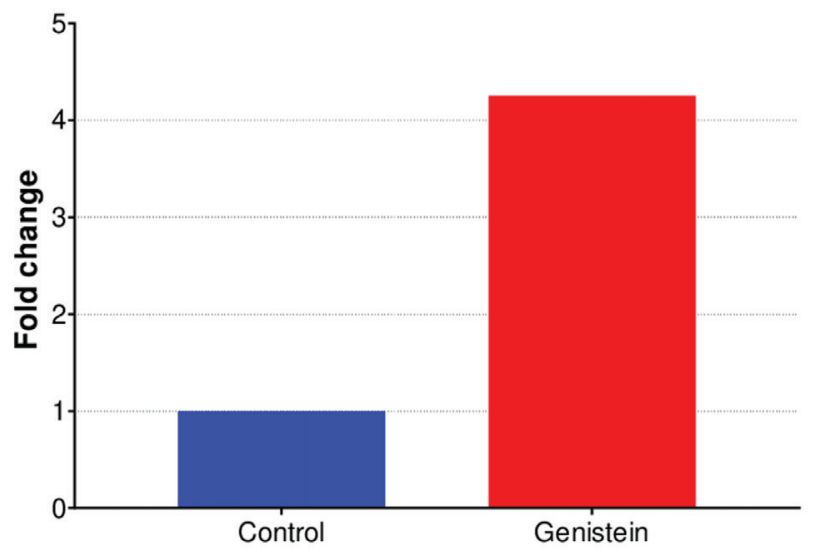

FIGURE 3. Apoptotic effect of Genistein at $I C_{50}$ Dose

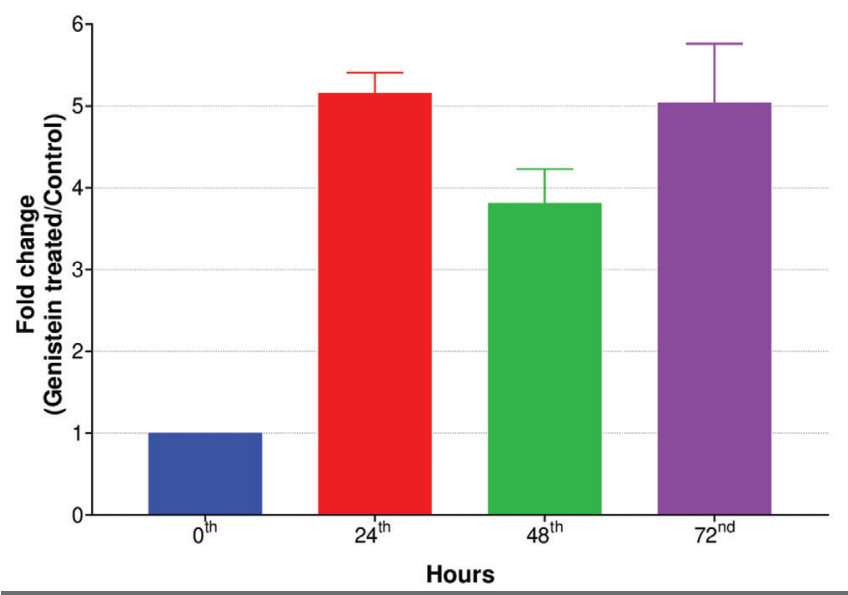

FIGURE 4. Fold change of hTERT gene expression in Genistein-treated HL-60 Cells. hTERT expressions were normalized to Porphobilinogen deaminase

ed HL-60 cells compared to the control group was found to be significantly 5.16, 3.81 and 5.04-fold down-regulation at $24^{\text {th }}, 48^{\text {th }}$ and $72^{\text {nd }}$ hours respectively ( $p<0.05$, Figure 4$)$.

\section{DISCUSSION}

Many studies have been conducted on the discovery of anti-cancer drugs from natural agents that can induce apoptosis in cancer cells. It has shown that genistein exhibits anti-cancer effects that involve the inhibition of cell proliferation and induce apoptotic cell death in various cancer cells. The results obtained with Annex V/PI double staining showed that when compared to the control group, genistein increased significant apoptosis in HL-60 cells over time and is dose-dependent (6). Genistein has been shown to induce apoptosis in hematological malignant cells through multiple mechanisms while maintaining normal cells from toxicity (9). In our study, we found that genistein increased apoptosis by approximately 4.25-fold in HL-60 cells. Yamasaki et al. (10) found that genistein (30 $\mu \mathrm{M})$ inhibited cell proliferation by inhibition of the $\mathrm{G} 2 / \mathrm{M}$ cell cycle in adult T-cell leukemia cells. Some naturally occurring flavonoids, including genistein (dose range $0-50 \mu \mathrm{m}$ ), have been shown to inhibit human promyelocytic leukemia cell lines (II).

Genistein has been found to suppress telomerase activity and hTERT gene expression levels in prostate cancer and brain tumor cells $(12,13)$. In the prostate cancer cell line (LNCAP), the anticancer effect of genistein has been investigated, and genistein has been shown to reduce hTERT and telomerase activity (I3). It has effects such as anti-telomerase, anti-cancer, anti-inflammatory, anti-proliferative on various cancer cells such as breast cancer, prostate, melanoma (12). Genistein has been shown to inhibit hTERT transcription, the catalytic subunit of human telomerase activity in the MCF-7 cancer cell line depending on time and dose (14). Telomerase is expressed at high levels in malignant gliomas. Ferrandon et al. (I5) found that the imetelstat telomerase inhibitor decreased cell proliferation and increased resistance to radiotherapy in both in vivo and in vitro studies. Telomere and telomerase enzyme have particularly been studied in chronic myeloid cells. Shorter telomere lengths were detected in chronic myeloid leukemia patients compared to healthy control groups (16). The synergistic effect of doxorubicin with telomerase inhibitor MSTI32 was found to induce apoptosis in pre-B ALL cells by down-regulation of c-Myc and telomerase-associated hTERT genes and up-regulation of $\mathrm{Bax} / \mathrm{Bcl}-2$ expressions and also to increase cell proliferation inhibition (17). In another study, thymoquinone and genistein have been found to induce apoptosis in anaplastic thyroid cancer cells, and decreased levels of hTERT mRNA expression after combined therapy (12). Malloy et al. (18) were showed that doses of genistein $(50 \mu \mathrm{M}$ and $100 \mu \mathrm{M})$ about $50 \%$ decrease in hTERT expression for endometrial cancer cell. Genistein is known to inhibit telomerase activity and cause telomere shortening. In their study with brain cells, genistein showed that growth inhibition associated with telomerase inhibition by inhibition of TR- and TERT mRNA (19). Jagadeesh et al. (20) showed that genistein reduced hTERT expression and transcriptional activity dose-dependent. In our study, we found that whether genistein suppresses hTERT gene expression. The hTERT gene is active in cancer cells and telomerase activity is high. The length of the telomere is thus preserved and the cancer cells are immortalized. Reduction of hTERT expression may also prevent the proliferation of cancer cells.

In conclusion, genistein can reduce hTERT activity and could be effective on apoptotic cells, and that this component can be used as an anti-cancer agent. One of the important limitations is that only a cell line has been studied in acute promyelocytic leukemia. The other is the counting of the cells with the eye in apoptosis assay. 
Ethics Committee Approval: Authors declared that the research was conducted according to the principles of the World Medical Association Declaration of Helsinki "Ethical Principles for Medical Research Involving Human Subjects", (amended in October 2013).

Peer-review: Externally peer-reviewed.

Author Contributions: Concept - T.B.O., C.K., G.S., C.G.; Design - T.B.O., C.K., G.S., C.G.; S.Y.S., C.B.A.; Supervision - T.B.O., C.K., C.G.; Resources - T.B.O., C.K., C.G.; Materials - T.B.O., C.K., C.G.; Data Collection and/or Processing - T.B.O., C.K., C.G., S.Y.S., C.B.A.; Analysis and/or Interpretation - T.B.O., C.K., G.S., C.G.; S.Y.S., C..B.A.; Literature Search - T.B.O., C..K., C.G.; Writing Manuscript - T.B.O., C.K., C.G.; Critical Review - T.B.O., C.K., C.G., S.Y.S., C.B.A.

Conflict of Interest: Authors have no conflicts of interest to declare.

Financial Disclosure: The authors declared that this study has received no financial support.

\section{REFERENCES}

I. Cammarata G, Augugliaro L, Salemi D, Agueli C, La Rosa M, Dagnino $L$, et al. Differential expression of specific microRNA and their targets in acute myeloid leukemia. Am J Hematol 20I0; 85(5): 33I-9. [Crossref]

2. Koshiishi C, i Kanazawa T, Vangrevelinghe E, Honda T, Hatakeyam S. Identification and characterization of a phenyl-thiazolyl-benzoic acid derivative as a novel RAR/RXR agonist. Heliyon 2019; 5(II): e02849. [Crossref]

3. Grandjenette C, Schnekenburger M, Gaigneaux A, Gérard D, Christov C, Mazumder A, et al. Human telomerase reverse transcriptase depletion potentiates the growth-inhibitory activity of imatinib in chronic myeloid leukemia stem cells. Cancer Lett 2019; pii: S03043835(19)30572-5.

4. Miri-Moghaddam E, Deezagi A, Soheili ZS. Downregulation of telomerase activity in human promyelocytic cell line using RNA interference. Ann Hematol 2009; 88(12): II69-76 [Crossref]

5. Li W, Frame LT, Hirsch S, Cobos E. Genistein and hematological malignancies. Cancer Lett 20I0; 296(I): I-8. [Crossref]

6. Hsiao YC, Peng SF, Lai KC, Liao CL, Huang YP, Lin CC, et al. Genistein induces apoptosis in vitro and has antitumor activity against human leukemia HL-60 cancer cell xenograft growth in vivo. Environ Toxicol 2019. [Crossref]

7. Sánchez Y, Amrán D, de Blas E, Aller P. Regulation of genistein-induced differentiation in human acute myeloid leukaemia cells (HL60, NB4) Protein kinase modulation and reactive oxygen species generation Biochem Pharmacol 2009; 77(3): 384-96. [Crossref]
8. Kasibhatla S, Amarante-Mendes GP, Finucane D, Brunner T, Bossy-Wetzel E, Green DR. Acridine orange/ethidium bromide (AO/EB) staining to detect apoptosis. Cold Spring Harbor Protocols 2006; 2006(3): pdb-prot4493. [Crossref]

9. Birt DF, Hendrich S, Wang W. Dietary agents in cancer prevention: flavonoids and isoflavonoids. Pharmacol Ther 200I; 90(2-3): 157-77. [Crossref]

10. Yamasaki M, Mine Y, Nishimura M, Fujita S, Sakakibara Y, Suiko M, et al. Genistein induces apoptotic cell death associated with inhibition of the NF-kB pathway in adult T-cell leukemia cells. Cell Biol Int 2013; 37(7): 742-7. [Crossref]

II. Hsiao YC, Peng SF, Lai KC, Liao CL, Huang YP, Lin CC, et al. Genistein induces apoptosis in vitro and has antitumor activity against human leukemia HL-60 cancer cell xenograft growth in vivo. Environ Toxicol 2019; 34(4): 443-56. [Crossref]

12. Özturk SA, Alp E, Yar Sağlam AS, Konac E, Menevse ES. The effects of thymoquinone and genistein treatment on telomerase activity, apoptosis, angiogenesis, and survival in thyroid cancer cell lines. $J$ Cancer Res Ther 2018; 14(2): 328-34.

13. Khaw AK, Yong JW, Kalthur G, Hande MP. Genistein induces growth arrest and suppresses telomerase activity in brain tumor cells. Genes Chromosomes Cancer 2012; 51(10): 961-74. [Crossref]

14. Li Y, Liu L, Andrews LG, Tollefsbol TO. Genistein depletes telomerase activity through cross-talk between genetic and epigenetic mechanisms. Int J Cancer 2009; 125(2): 286-96. [Crossref]

15. Ferrandon S, Malleval C, El Hamdani B, Battiston-Montagne $P$, Bolbos R, Langlois JB, et al. Telomerase inhibition improves tumor response to radiotherapy in a murine orthotopic model of human glioblastoma. Mol Cancer 2015; 14: 134. [Crossref]

16. Biray Avci C, Dogan F, Ozates Ay_NP, Goker Bagca B, Abbaszadeh Z, Gunduz C. Effects of telomerase inhibitor on epigenetic chromatin modification enzymes in malignancies. J Cell Biochem 2018; II9(12): 9817-24. [Crossref]

17. Ghasemimehr N, Farsinejad A, Mirzaee Khalilabadi R, Yazdani Z, Fatemi $A$. The telomerase inhibitor MST-312 synergistically enhances the apoptotic effect of doxorubicin in pre-B acute lymphoblastic leukemia cells.Biomed Pharmacother 2018; 106: 1742-50. [Crossref]

18. Malloy KM, Wang J, Clark LH, Fang Z, Sun W, Yin Y, et al. Novasoy and genistein inhibit endometrial cancer cell proliferation through disruption of the AKT/mTOR and MAPK signaling pathways. Am J Transl Res 2018 Mar 15; I0(3): 784-95.

19. Khaw AK, Yong JW, Kalthur G, Hande MP. Genistein induces growth arrest and suppresses telomerase activity in brain tumor cells. Genes Chromosomes Cancer 2012; 5I(10): 961-74. [Crossref]

20. Jagadeesh S, Kyo S, Banerjee PP. Genistein represses telomerase activity via both transcriptional and posttranslational mechanisms in human prostate cancer cells. Cancer Res 2006; 66(4): 2107-15. [Crossref] 